\title{
Serotonin Activates S6 Kinase in a Rapamycin-Sensitive Manner in Aplysia Synaptosomes
}

\author{
Asad Khan, Antonio M. Pepio, and Wayne S. Sossin \\ Department of Neurology and Neurosurgery, Montreal Neurological Institute, McGill University, Montreal, \\ Quebec H3A 2B4, Canada
}

The identification of tags that can specifically mark activated synapses is important for understanding how long-term synaptic changes can be restricted to specific synapses. The maintenance of synapse-specific facilitation in Aplysia sensory to motor neuron cultures can be blocked by inhibitors of translation and by the drug rapamycin, which specifically blocks a signaling pathway that regulates phosphorylation of translational regulators. One important target of rapamycin is the phosphorylation and subsequent activation of S6 kinase. To test whether S6 kinase is the target for the ability of rapamycin to block synapse-specific facilitation in Aplysia, we cloned Aplysia S6 kinase, its substrate S6, and the S6 kinase kinase phosphoinositide-dependent kinase 1 (PDK-1). Serotonin, which induces synapse-specific facilitation, increased phosphorylation of Aplysia S6 kinase at threonine 399 in a rapamycin-sensitive manner in Aplysia synaptosomes. The

The ability to regulate translation locally at synaptic contacts is an attractive mechanism for limiting global changes in neuronal gene expression to specific synapses (Steward and Banker, 1992; Sossin, 1996; Schuman, 1997; Wells et al., 2000). In the marine mollusk Aplysia californica, the retention of long-term facilitation after addition of serotonin (5-HT) is dependent on local translation and is blocked by local application of rapamycin to the synapse (Casadio et al., 1999). Addition of 5-HT also leads to increases in the rate of translation that are sensitive to rapamycin (Yanow et al., 1998; Casadio et al., 1999), suggesting that the increase in the translation rate may be important for the retention of long-term facilitation.

The major target for rapamycin in cells is the FKPB-12 and rapamycin-associated protein FRAP (Brown and Schreiber, 1996). Activation of FRAP leads to increased S6 kinase activity (Brown et al., 1995), which in turn leads to phosphorylation of S6 and increased translation of a set of proteins, including ribosomal proteins and translation factors (Jefferies et al., 1997; Peterson and Schreiber, 1998; Dufner and Thomas, 1999). Disruption of S6 kinase leads to growth defects in both mammals and invertebrates (Shima et al., 1998; Montagne et al., 1999).

Received Sept. 8, 2000; revised Oct. 20, 2000; accepted Oct. 30, 2000

This work was supported by Medical Research Council of Canada (MRC) Grant MT-15121 to W.S.S. A.K. is supported by an MRC MD-PhD Studentship, and A.M.P is supported by an MRC PhD Studentship. W.S.S. is a recipient of a Chercheur-Boursier from Fonds de la Recherche en Sante du Quebec. We thank Xiaotang Fan for technical assistance. We thank Phil Barker and Peter McPherson for comments on this manuscript.

Correspondence should be addressed to Wayne Sossin, Montreal Neurological Institute, 3801 University Street, Montreal, Quebec H3A 2B4, Canada. E-mail: mdws@musica.mcgill.ca.

Copyright () 2001 Society for Neuroscience 0270-6474/01/210382-10\$15.00/0 phosphorylation of threonine 399 by 5-HT was independent of phosphoinositide-3 kinase, dependent on PKA and PKC, and occluded by the phosphatase inhibitor calyculin-A. 5-HT also increased S6 kinase activity and led to increased phosphorylation of S6 in synaptosomes. 5-HT increased levels of S6 in synaptosomes because of a rapamycin-sensitive increase in translation-stabilization of S6. Aplysia PDK-1 bound to and phosphorylated Aplysia S6 kinase but only modulated phosphorylation of threonine 399 indirectly. These results suggest a mechanism by which the levels of translation factors can be increased specifically at activated synapses generating a longlasting synaptic tag.

Key words: synaptic plasticity; S6 kinase; Aplysia; synaptic tagging; rapamycin; serotonin; phosphoinositide-dependent protein kinase; S6; translation

S6 kinase activation requires multiple phosphorylation events that are regulated in a complex manner (Dufner and Thomas, 1999). Important sites in the inhibitory C terminus (Han et al., 1995) are similar to those phosphorylated by FRAP in eukaryotic initiation factor 4E binding protein (eIF4E-BP) and may be direct targets of FRAP (Gingras et al., 1998; Isotani et al., 1999). Phosphorylation of a threonine in the activation loop of S6 kinase is critical for activation; this site is phosphorylated by phosphoinositide-dependent kinase 1 (PDK-1) (Alessi et al., 1998; Pullen et al., 1998; Weng et al., 1998). Phosphorylation of another site, often called the PDK-2 site, is also required for S6 kinase activation (Pearson et al., 1995). Phosphorylation at this site is the most tightly linked with activation of the kinase and is the most sensitive to rapamycin (Pearson et al., 1995; Weng et al., 1998). Although there is some evidence that this site is phosphorylated by FRAP (Burnett et al., 1998a; Isotani et al., 1999), rapamycin sensitivity may also occur through FRAP-mediated inhibition of a calyculin-sensitive phosphatase (Dennis et al., 1996; Peterson et al., 1999; Westphal et al., 1999). These regulatory steps have been examined in cell lines; however, there is little data regarding the mechanism of activation of S6 kinase in neurons.

We have cloned S6 kinase in Aplysia to determine whether it may play a role in the rapamycin-sensitivity of long-term facilitation. We find that 5-HT increased S6 kinase phosphorylation at the PDK-2 site in synaptosomes and that this activation is blocked by rapamycin but not by PI-3 kinase inhibitors. Activation of S6 kinase leads to an increase in phosphorylation and levels of the S6 protein, suggesting that 5-HT may induce a synapse-specific increase in the production of translation factors in Aplysia through activation of S6 kinase. 


\section{MATERIALS AND METHODS}

Materials. Aplysia californica (75-125 gm) were obtained from Marine Specimens Unlimited (Pacific Palisades, CA) or University of Miami National Institutes of Health Aplysia resource facility (Miami, FL) and maintained in an aquarium for at least $3 \mathrm{~d}$ before experimentation. The animals were first placed in a bath of isotonic $\mathrm{MgCl}_{2}$-artificial seawater (1:1, $\mathrm{v} / \mathrm{v}$ ) and then anesthetized by injection with isotonic $\mathrm{MgCl}_{2}$ solution. The pharmacological agents LY294002, Chelerythrine, KT5720, calyculin-A, and rapamycin were purchased from Calbiochem (La Jolla, CA).

Cloning of S6 kinase, PDK, and S6. To create Aplysia nervous system cDNA, pleural, pedal, and abdominal ganglia were dissected from the animals, immediately frozen in liquid nitrogen, and then processed using the Qiagen RNEasy Minikit (Qiagen, Santa Clara, CA) to obtain total RNA. cDNA template was made using Superscript II reverse transcriptase (Life Technologies, Gaithersburg, MD). Finally, cDNA product was used as a template in PCR to amplify fragments of S6, S6 kinase, and PDK-1 using degenerate primers (see below). These fragments were cloned using the TOPO TA cloning kit (Invitrogen, Carlsbad, CA). The cloned fragments were labeled with $\left[{ }^{32} \mathrm{P}\right] \mathrm{ATP}$ using PCR and used to screen a $\lambda$-ZAP cDNA library (gift of Dr. J. H. Schwartz, Columbia University College of Physicians and Surgeons, New York, NY). From this screen, cDNAs containing the full coding region of S6 and S6 kinase were isolated, but for PDK-1, the longest clone isolated was missing a small fragment of the $3^{\prime}$ end and this fragment could not be cloned from this library. To isolate the $3^{\prime}$ end, we used $3^{\prime}$ rapid amplification of cDNA ends (RACE) using nested primers from the sequenced clone and nested primers from the vector sequences of a plasmid cDNA library (Bartsch et al., 1995). This screen resulted in isolation of the $3^{\prime}$ stop codon and additional PDK-1 3'untranslated region. All sequencing was done on both strands using the services of The W. M. Keck Biotechnology Resource Laboratory (Yale University, New Haven, CT) and Bio S\&T Inc. (Montreal, Quebec, Canada). The sequences have been submitted to the GenBank database with accession numbers AF294916 (S6 kinase), AF294917 (PDK), and AF29418 (S6). The following primers were used: S6 kinase degenerate 5' primer (YAFQT), 5-TAYGCNTTYCARAC; S6 kinase degenerate $3^{\prime}$ primer (KPENI), 5'-ATRTTYTCNGGYTT; S6 degenerate $5^{\prime}$ primer (KQGFPM), 5'-AARCARGGNTTYCCNATG; S6 degenerate $3^{\prime}$ primer (KEDDV), 5'-ACRTCRTCYTCYTT; PDK-1 degenerate $5^{\prime}$ primer (KGLFA), 5'-AARGGNYTNTTYGC; PDK-1 degenerate $3^{\prime}$ primer (KGEIPW), 5'-CCANGGDATYTCNCCYTT; PDK-1 5' primer $13^{\prime}$ RACE, 5'-TTGTGGAGGACAACCTGAT; PDK-1 5'primer 2 3' RACE, 5'-CGCCAGA-GGCCAAGAAC; PDK-1 (K-N) O5, 5'-CCACAAGCTCAGGGCA-CAG; PDK-1 (K-N) I5, 5'-GCAATTAATGTGTGTGACAAGAA-GCAC; PDK-1 (K-N) I3, 5'-ACACCATTAATTGCAAATTCTTT-TTGAGT; and PDK (K-N) O3, 5'-CGTATTCTGCGGTGCCGAC.

Construction of plasmids. To make a baculovirus transfer vector for S6 kinase, we cut the cDNA clone with PstI and XhoI and inserted it into BB4 (Invitrogen) cut with the same enzymes. To generate a baculovirus for myristylated (constitutively active) phosphoinositide-3 (PI-3) kinase, a clone was generously provided by Dr. David Kaplan (Montreal Neurological Institute), and we inserted it into BB4 at the BamHI site. To generate a baculovirus for PDK-1, we used a triple ligation cutting the long PDK-1 clone with BamHI and DraI, the clone containing the $3^{\prime}$ fragment with $\operatorname{Dra\mathrm {I}}$ and $K p n \mathrm{I}$, and inserting these two fragments into BB4 cut with BamHI and KpnI. Mutating the catalytic lysine in PDK-1 was done with a two-step mutagenic procedure using PCR. First-round PCR used PDK-1 in BB4 as a template and either the outside $5^{\prime}$ primer (O5) and the inside $3^{\prime}$ primer (I3) or the inside $5^{\prime}$ primer (I5) and the outside $3^{\prime}$ primer (O3) (see above for primers). The products from the first-round synthesis were combined and used as the template for secondround synthesis using $\mathrm{O} 5$ and $\mathrm{O} 3$. The resultant product was cut with $B s t$ EII and DraIII and inserted into PDK-1 in the BB4 vector. A new AseI was formed by the mutagenesis and was used to confirm the cloning. A fragment of PDK-1 containing the kinase domain, the PH domain, and $\sim 75 \%$ of the unconserved $5^{\prime}$ domain (starting at residue 130) was used to make a glutathione $S$-transferase (GST) fusion protein by cutting out both PDK-1 and PDK-1 (K-N) from the BB4 vector with NcoI and NheI, filling in the ends with Klenow, and inserting the fragments into the pGEX 5x-1 (Amersham Pharmacia Biotech, Arlington Heights, IL) vector cut with SmaI. A GST-S6 fusion protein was made by cutting S6 out of the cDNA clone with EcoRI and inserting it into pGEX 3.1 (Amersham Pharmacia Biotech) cut with EcoRI.
Production of antibodies. A peptide from S6 kinase (CNGYDTSAQEDMT- $\mathrm{NH}_{2}$ ) or PDK-1 (CIQEVWKKYYDADS-COOH) containing a cysteine residue added to the $\mathrm{N}$ terminal was synthesized and then coupled to both BSA maleimide and SulfoLink columns (Pierce, Rockford, IL). The coupled peptides were injected into rabbits with Titer-Max (CytRx, Norcross, GA) adjuvant four times at intervals of 1 month. The resultant sera were affinity purified over the SulfoLink columns and concentrated to at least $1 \mathrm{mg} / \mathrm{ml}$. For S6, the antigen was the S6 fusion protein. The resultant sera recognized only the S6 doublet on Western blots and was not additionally purified.

Immunoblots. Western blots were performed as described previously (Dyer et al., 1996) with the S6 kinase antibody at $2 \mu \mathrm{g} / \mathrm{ml}$ dilution, the S6 antibody at a 1:3000 dilution of serum, the PDK antibody at $2 \mu \mathrm{g} / \mathrm{ml}$, the phosphopeptide antibody to the PDK-2 site $(1 \mu \mathrm{g} / \mathrm{ml}$; New England Biolabs, Beverly, MA), and goat anti-rabbit, horseradish peroxidaseconjugated secondary antibody at $1 \mu \mathrm{g} / \mathrm{ml}$. The New England Biolabs antibody was incubated overnight at $4^{\circ} \mathrm{C}$, whereas all other primaries were incubated at room temperature for $2 \mathrm{hr}$. Blots were then developed with ECL (Amersham Pharmacia Biotech).

Expression of S6 kinase, PDK, and PI-3 kinase in SF9 cells. Transfer vectors for S6 kinase, PDK, and PDK (K-N) and PI-3 kinase were recombined with wild-type baculovirus (Invitrogen), and high titer stocks were generated. For infections, a multiplicity of infection (MOI) of 5 for each virus was used. When multiple viruses were used in a single experiment, the same MOI was used, but double (or triple for three virus infections) amounts of protein was loaded onto gels for quantitation.

PI-3 kinase assays. Supernatant and membrane fractions from SF9 cells were incubated with mixed phosphoinositides (Sigma, St. Louis, MO) and $10 \mu \mathrm{M}$ ATP $\left(1 \mu \mathrm{Ci}\right.$ of $\left.\left[\gamma^{-32} \mathrm{P}\right] \mathrm{ATP}\right)$ in $10 \mathrm{mM}$ HEPES buffer. The lipids were extracted with chloroform and separated by thin layer chromatography next to markers generated using purified PI-3 kinase. Infection with the activated form of PI-3 kinase led to a 10- to 50-fold increase in levels of phosphoinositide $(3,4,5)$ P3 generated from membranes of SF9 cells (data not shown)

Phosphorylation of S6 and S6 kinase in synaptosomes. Synaptosomes were prepared as described previously (Chin et al., 1989). This protocol gives a P1 pellet containing particulate proteins, two soluble fractions (S2 and S3), and two synaptosome-containing fractions, P3, which contains the purest synaptosomes, and $\mathrm{P} 2$, which contains the greatest amount of synaptosomes but of lesser purity (Chin et al., 1989). Initially, P2 and P3 fractions were tested separately but, because no differences were observed in the amount of S6 or S6 kinase phosphorylated (data not shown), later experiments used a combination of P2 and P3. Synaptosomes, prepared from four to five nervous systems were used for single experiments, usually aliquoted into $8-12$ individual tubes. All conditions were done in duplicate. An initial time course with 5-HT suggested that a 20 min incubation was optimal for increased threonine 399 (Thr 399) phosphorylation and 25 min for S6 phosphorylation (data not shown). All experiments for S6 kinase phosphorylation used a 20 min incubation with 5-HT, and all experiments with S6 used 25 min incubations. We have only used one concentration of 5-HT $(20 \mu \mathrm{M})$. We have previously used this concentration to induce rapamycin-sensitive translational changes in Aplysia ganglia (Yanow et al., 1998), and it is similar to concentrations used to induce the rapamycin-sensitive change at Aplysia synapses (Casadio et al., 1999). Pharmacological inhibitors were applied at the same time as 5-HT. At the end of the time period, sample buffer was added to the synaptosomes, and they were boiled at $90^{\circ} \mathrm{C}$ for $5 \mathrm{~min}$. Nine percent SDS-page gels were run until the $46 \mathrm{kDa}$ marker was at the bottom of the gel to optimize separation of the post-translationally modified S6 kinase. Blots were first probed with the anti-phosphopeptide antibody and then reprobed for S6 kinase. Twelve percent SDS gels were run until the dye reached the end of the gel for quantitation of S6 because we were unable to resolve both post-translational modifications in the same gel system.

Quantitation of synaptosome phosphorylation. All gels were scanned and quantitated using NIH Image using the uncalibrated optical density function. We have found that this leads to a broad range in which results are linear (Nakhost et al., 1999). We standardized the phosphopeptide immunoreactivity with the S6 kinase immunoreactivity for each lane. Duplicates for each condition were then averaged, and the percentage change from control was calculated: ((experimental - control)/control) * 100. To calculate the effect of 5-HT, the percentage change from pharmacological agent alone was calculated. For S6, the percentage of upper band was calculated from the two well separated bands. Total S6 was standardized to ponceau stains of total protein to ensure gels were equally loaded with protein. Duplicates for each condition were then 
Figure 1. Cloning of S6 kinase. A comparison of the Aplysia S6 kinase and rat S6 kinase is shown. Identical residues are shaded. Known phosphorylation sites in rat S6 kinase and putative sites in Aplysia are in a darker shade. In particular, the positions of the PDK-1, PDK-2, and C-terminal sites are outlined. Also shown are the region required for rapamycin sensitivity and the boundaries of the kinase domain.

averaged, and the percentage change from control was calculated: ((experimental - control)/control) $* 100$. All statistical tests were paired $t$ tests between control and experimental values.

S6 kinase assays. Synaptosomes were treated with low $\mathrm{Ca}^{2+}$-seawater or low $\mathrm{Ca}^{2+}$-seawater and $20 \mu \mathrm{M} 5$-HT for $20 \mathrm{~min}$. The synaptosomes were lysed with immunoprecipitation buffer (1\% Triton X-100, $150 \mathrm{~mm}$ $\mathrm{NaCl}, 0.5 \mathrm{~mm}$ 2-mercaptoethanol, $20 \mathrm{mg} / \mathrm{ml}$ aprotinin, $5 \mathrm{~mm}$ benzamadine, $0.1 \mathrm{~mm}$ leupeptin, $50 \mathrm{~mm} \mathrm{NaF}, 5 \mathrm{~mm}$ sodium pyrophosphate, $\mathrm{pH}$ 8.5, $1 \mu \mathrm{M}$ microcystin, and $50 \mathrm{~mm}$ Tris, $\mathrm{pH} 7.8$ ). Nonsolubilized proteins were spun out at $100,000 \times g$, and the supernatant was incubated with anti-S6 kinase serum $(5 \mu \mathrm{l})$ or preimmune serum $(5 \mu \mathrm{l})$ that had been precoupled to protein-A beads. The beads were then spun down and washed extensively, and buffer was changed to kinase buffer (50 mM Tris, $\mathrm{pH} 7.5$, and $10 \mathrm{~mm} \mathrm{MgCl}_{2}$ ). Substrate peptides derived from the Aplysia S6 sequence (see below) were added $(20 \mu \mathrm{M})$, and the reaction was started with [ $\left.{ }^{32} \mathrm{P}\right]$ ATP $(1 \mu \mathrm{Ci}, 50 \mu \mathrm{M}$ final concentration $)$. Supernatants were placed on phosphocellulose filters and washed with $1 \%$ cold ATP and then four times with $0.25 \%$ phosphoric acid before scintillation counting.

S6 peptides for assay. We synthesized two peptides based on the two putative S6 kinase sites (R/KxR/KxxS/T) in Aplysia S6 (RKRANSRA and RRAKGDSIA). These peptides were slightly modified from the S6 sequences (RKRSNSRS and RSKGDSIA). We added positive charges at the $\mathrm{N}$ terminus of the second peptide to ensure binding to phosphocellulose papers. We also converted serines outside the S6 kinase site to alanine to reduce cross-reactivity with other kinases.

\section{RESULTS}

\section{Cloning of Aplysia S6, S6 kinase, and PDK-1}

To determine whether phosphorylation of S6 is a target for the rapamycin-sensitive pathway in Aplysia, we cloned Aplysia S6, S6 kinase, and the S6 kinase kinase PDK-1 (Alessi et al., 1998; Pullen et al., 1998). Using degenerate primers based on sequence homology between vertebrate and invertebrates, we isolated fragments of the proteins and then used these fragments as a probe to screen an Aplysia cDNA library. Several clones were isolated for each protein and, based on mapping, the longest isolate was completely sequenced on both strands. For S6 and S6 kinase, the entire open reading frame was encoded on the sequenced clone (Figs. 1, 2). For PDK-1, this clone was lacking the $3^{\prime}$ end of the $\mathrm{PH}$ domain and the stop codon, and further screening of the library did not result in longer clones. Therefore, we used 3' RACE to isolate an additional fragment that contained a stop codon to give the entire open reading frame (Fig. 3).

The sequence of S6 kinase contained an initiator methionine with a classic Kozak sequence preceded by a stop codon in frame, identifying it as the initiator methionine (data not shown). This 
Ap1 S6 MKLNISYPATGCQKLIEVDDEKKLRPFYDKRISAELSADCLGDEWKGYVV 50 Mus S6 MKLNISFPATGCQKLIEVDDERKLRTFYEKRMATEVAADALGEEWKGYVV 50

Apl S6 RISGGNDKQGFPMKQGVLTATRVRLLLDKNHSCYRPRRTGERKRKSVRGC 100

Mus S6 RISGGNDKQGFPMKQGVLTHGRVRLLLSKGHSCYRPRRTGERKRKSVRGC 100

Ap1 S6 IVDSNLSVLSLVIIKKGEQDIPGLTDKTIPRRLGPKRASKIRKLFNLSKE 150 Mus S6 IVDANLSVLNLVIVKKGEKDIPGLTDTTVPRRLGPKRASRIRKLFNLSKE 150

Apl S6 DDVRQYVVRRPLPERDGKKAKSKAPKIQRLVTPVVLQRKRARMALKKKRV 200 Mus S6 DDVRQYVVRKPL-NKEGKKPRTKAPKIQRLVTPRVLQHKRRRIALKKQRT 199

Apl S6 TKKREDHAEYTKLLAQRMKEAKERKMERKRSNSRSKGDSIRESTSKK. MUS S6 KKNKEEAAEYAKLLAKRMKEAKEKRQEQIAKRRRLSSLRASTSKSESSQK
247 Figure 2. Cloning of Aplysia S6. A comparison of Aplysia and rat $\mathrm{S} 6$ sequences. Identical residues are shaded. Sites matching the S6 kinase consensus sequence are in bold.

Ap1 PDK MDGAEGSVVPLGEDVRTCKGASGQGTSVSESGANGAAGDCATEQAEHSNGLSEKMSNLNSISSSDTPVDN 70

Ap1 PDK TQEQDSVTGVCRSLSAEPEMEVGTQPVFTDLEGKVGDNVEGSEEYIEDIKETSPSPCESMDSSRPGGDTS 140

Ap1 PDK RESSECPSSLSYRDNMSSQMSMASYPGDIRNTTPDLPMSMSRESSFAFLREESVVSNSSSNQDKEEFLSA 210

Ap1 PDK RESLESSSSAGSCRSGGNLGIKPGELMNQLVEGPLITLPPAQLSSGSSSAPISSPQAESAAPTPSGQTLS 280

Apl PDK GTHVPQAQGTVEEAQPAPPTHHPTYAEVAHHSVGSNAPRSSATSAGGDQGSTDKSTPSSAPTQAPSSGST 350 Hum PDK --

Kinase Domain Start

$\rightarrow$

APl PDK AQSSAATAAANKARVKKTPNDFIFGKVIGEGSYSTVYLAKEVSTQKEFAIKVCDKKHLIRERKTHFVMRE 420 HUM PDK GAGSLQHAQPPPQPRKKRPEDFKFGKILGEGSFSTVVLARELATSREYAIKILEKRHIIKENKVPYVTRE 131

AP1 PDK KEVLMKLDHPFFIRLAYTFQDPERLYYTLTYARNGELLGYLHKLSAFDVPCTRFYTAEIVLALEYLHSLG 490 HUM PDK RDVMSRLDHPFFVKLYFTFQDDEKLYFGLSYAKNGELLKYIRKIGSFDETCTRFYTAEIVSALEYLHGKG 201

APl PDK IVHRDLKPENILLSEDMHIKITDFGTSKILSSDSKPEVKRKNSFVGTAEYVSPEVLNNQPANFGSDLWGL 560 HUM PDK IIHRDLKPENILLNEDMHIQITDFGTAKVLSPESKQA--RANSFVGTAQYVSPELLTEKSACKSSDLWAL 269

Ap1 PDK GCIIYQCLSGSLPFRCGNEYQTFQKIVKAEYDFPEGFHPHAKDLVQKLLVIEPADRLG---MADMGDLKR 627 HUM PDK GCIIYQLVAGLPPFRAGNEYLIFQKIIKLEYDFPEKFFPKARDLVEKLLVLDATKRLGCEEMEGYGPLKA 339

\section{Kinase Domain End}

$\leftarrow$

AP1 PDK HPFYEGVDWENLPQSTPPKLMPYLPATANNPEFWGQDHRTGFDDQRLAEIITGQGVDGTQSPELEEVVRA 697 HUM PDK HPFFESVTWENLHQQTPPKLTAYLPAMSEDDEDCYGNYDNLLSQFGCMQVSSSSSSHSLSASDTGLPQRS 409

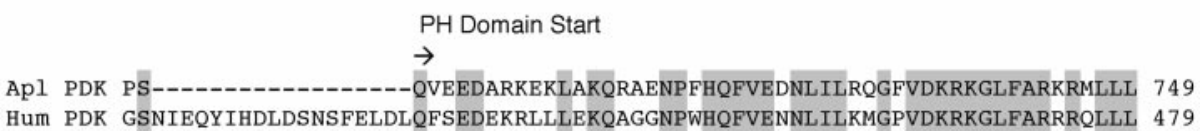

Hum PDK GSNIEQYIHDLDSNSFELDLQFSEDEKRLLLEKQAGGNPWHQFVENNLILKMGPVDKRKGLFARRRQLLL 479

PH Domain End

$\leftarrow$

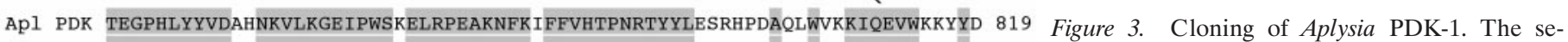

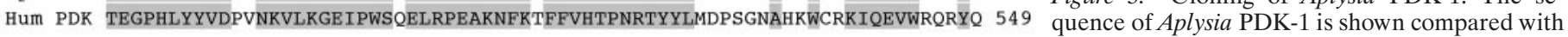

Apl PDK DADS.

Hum PDK SHPDAAVQ. human PDK-1. Identical residues are shaded. The 823 boundaries of the kinase domain and the $\mathrm{PH}$ 557 domain are indicated.

sequence is clearly an S6 kinase based on strong homology to vertebrate and invertebrate S6 kinases (47\% identity to rat S6 kinase) (Fig. 1). The S6 kinase sequence contains many of the conserved phosphorylation sites that have been identified in S6 kinase, including the PDK-1 site, the PDK-2 site, a site preceding the PDK-2 site that is an autophosphorylation site in PKCs, and a serine-proline site in the autoinhibitory domain (Fig. 1). There is also conservation of an acidic region in the N-terminal domain thought to be important for rapamycin sensitivity (Fig. 1). One difference between the Aplysia S6 kinase and the vertebrate forms is the number of C-terminal phosphorylation sites; Aplysia has only one, whereas vertebrates have more than four sites in this region (Fig. 1). Also, the binding site for the PDZ-containing protein neurabin in the $\mathrm{C}$ terminal of S6 kinase (Burnett et al., 1998b) is not conserved in Aplysia. Drosophila and Caenorhabditis elegans $\mathrm{S} 6$ kinases also have fewer S/T-P sites in the $\mathrm{C}$ terminus and also lack the neurabin-binding site (Stewart et al., 1996; The C. elegans Sequencing Consortium, 1998).

The sequence of S6 stopped shortly after the initiating methionine. However, the high homology to other S6 proteins allowed 


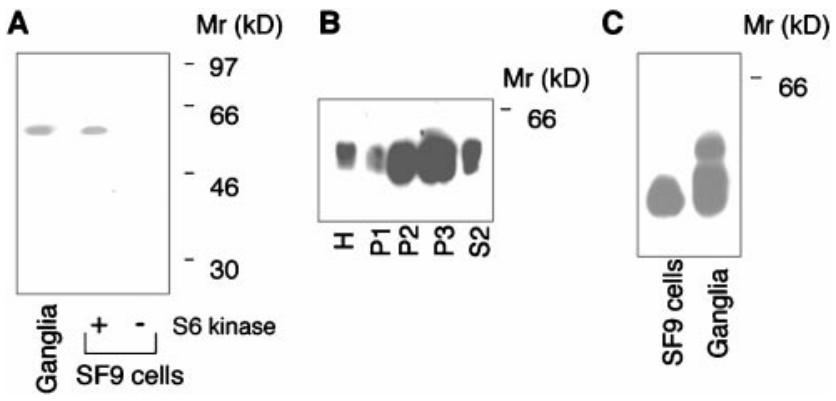

Figure 4. Characterization of the Aplysia S6 kinase. A, The antibody to S6 kinase recognizes an $\sim 60 \mathrm{kDa}$ protein in both Aplysia nervous system (20 $\mu \mathrm{g}$ of homogenate) and SF9 cells infected with a baculovirus encoding Aplysia S6 kinase. No immunoreactivity is seen in uninfected SF9 cells. $B$, S6 kinase is enriched in synaptosomes; $10 \mu \mathrm{g}$ from each fraction of a synaptosome preparation $(H$, homogenate; $P 1, P 2, P 3$, and $S 2)$ were loaded on a gel and blotted for S6 kinase. The fraction most enriched for synaptosomes (P3) contained the highest levels of S6 kinase. $C$, Optimizing gel separation and running time reveals multiple immunoreactive bands in ganglia (20 $\mu \mathrm{g}$ of homogenate) and band(s) in SF9 cells that comigrate with the faster migrating band(s) from nervous system.

for tentative assignment of the initial methionine (Fig. 2). There is very high conservation of S6 over evolution (76\% sequence identity between mouse and Aplysia), except in the region of phosphorylation, in which phosphorylation sites are always present but the absolute sequence conservation is lower (Fig. 2).

The sequence of PDK-1 contained an initiator methionine with a classic Kozak sequence preceded by a stop codon in frame, identifying it as the initiator methionine (data not shown). This clone is highly homologous to human PDK-1 in both the $\mathrm{PH}$ $(72 \%)$ and the kinase domain (53\%), but contains a long $\mathrm{N}$-terminal domain that is not conserved (Fig. 3).

\section{Characterization of S6 kinase}

An antibody was raised to a C-terminal peptide from the nonconserved C-terminal domain of S6 kinase. The antibody recognized a single band migrating at $\sim 60 \mathrm{kDa}$ in both SF9 cells expressing Aplysia S6 kinase and Aplysia ganglia (Fig. 4A). Because the physiological response to rapamycin was seen in Aplysia synapses, we next determined whether S6 kinase was detected in synaptosomes. Indeed, we found that S6 kinase was present in synaptosomes (Fig. 4B), similar to the distribution of vertebrate S6 kinase (Burnett et al., 1998b). Using gels optimized for separation in this region, there are multiple bands recognized by this antibody in Aplysia ganglia (Fig. 4C). These multiple bands probably consist of differentially phosphorylated forms of S6 kinase, similar to vertebrate S6 kinase (Dufner and Thomas, 1999). S6 kinase expressed in SF9 cells comigrates with the lower bands, consistent with reduced phosphorylation of the protein when overexpressed in SF9 cells (Fig. 4C).

\section{5-HT increases phosphorylation of threonine 399 in a rapamycin-sensitive, $\mathrm{PI}-3$ kinase-insensitive manner}

To determine whether 5-HT could activate S6 kinase, we used a commercial anti-phosphopeptide antibody to the mammalian PDK-2 site Thr 399 in Aplysia, because this site is highly conserved (Fig. 1) and studies have suggested that it is most closely linked with S6 kinase activity (Weng et al., 1998). Indeed, this antibody recognized a band that corresponded to the size of the highest band observed with the total S6 kinase antibody (Fig. 5A). Treating synaptosomes with 5 -HT induced a specific increase in the band recognized by the anti-phosphopeptide antibody (Figs.
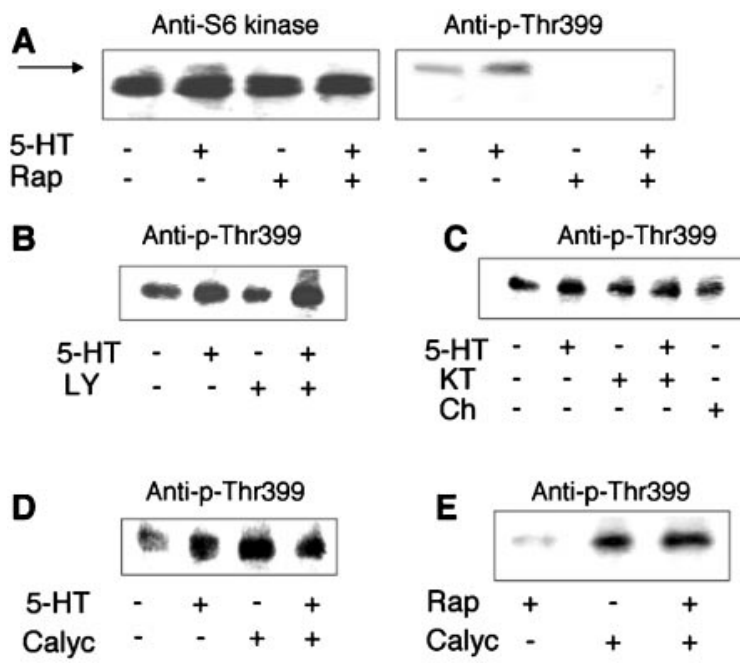

Figure 5. 5-HT increases Thr 399 phosphorylation. $A$, Synaptosomes were treated with low $\mathrm{Ca}^{2+}$-seawater or low $\mathrm{Ca}^{2+}$-seawater and $20 \mu \mathrm{M}$ 5 -HT for $20 \mathrm{~min}$ in the presence or absence of pharmacological inhibitors. Samples were immediately put in Laemmli's buffer, boiled and separated on SDS-PAGE gels, transferred to nitrocellulose, and blotted with a commercial antibody to the PDK-2 site (Anti-p-Thr399). The blots were then stripped and reprobed with the antibody to S6 kinase (Anti-S6 kinase). The antibody to the PDK-2 site only reacts with the slowest migrating S6 kinase band (arrow). 5-HT increases both Thr 399 phosphorylation and the amount of protein running in the slowest migrating band (arrow). Rapamycin (Rap; $20 \mathrm{~nm}$ ) strongly decreases Thr 399 phosphorylation and blocks the effect of 5-HT. B, Twenty micromolar LY294002 (LY) does not prevent 5-HT increases in Thr 399 phosphorylation. $C$, Inhibitors of PKA [KT5720 $(K T), 5 \mu \mathrm{M}]$ and PKC [chelerythrine $(C h) 10 \mu \mathrm{M}$ ] both block the effects of 5-HT on Thr 399 phosphorylation. D, Calyculin-A (Calyc; $100 \mathrm{nM})$, a phosphatase inhibitor, greatly increases Thr 399 phosphorylation and occludes the effect of 5-HT. E, Rapamycin does not block the effects of calyculin-A.

$5 A$, quantitated in $6 A$ ). Importantly, rapamycin significantly reduced immunoreactivity with the anti-phosphopeptide antibody (Figs. $5 A$, quantitated in $6 A$ ). Rapamycin also blocked the ability of 5-HT to increase phosphorylation of S6 kinase at Thr 399 (Figs. $5 A$, quantitated in $6 B$ ).

We conducted a series of experiments to determine the mechanism by which 5-HT increases phosphorylation of Thr 399 in synaptosomes. In vertebrates activation of S6 kinase by multiple pathways depends on PI-3 kinase activation (Dufner and Thomas, 1999).To determine whether 5-HT activated Thr 399 phosphorylation through PI-3 kinase, we examined the effects of a PI-3 kinase inhibitor (LY294002). LY294002 significantly decreased phosphorylation of S6 kinase at Thr 399 (Figs. 5C, quantitated in $6 A$ ). However, the effect of 5-HT on LY294002-treated synaptosomes was not blocked, because 5-HT increased Thr 399 phosphorylation, even in the presence of LY294002 (Figs. 5B, quantitated in $6 B$ ). Thus, 5 -HT does not activate phosphorylation of S6 kinase through activation of PI-3 kinase.

An increase in translation mediated by 5-HT in pleural ganglia was blocked by rapamycin (Yanow et al., 1998). This increase was also blocked by inhibitors of PKA and PKC (Yanow et al., 1998). To determine whether this inhibition could be attributable to inhibition of S6 kinase, we determined the effect of PKA and PKC inhibitors on 5-HT-mediated phosphorylation of Thr 399. Both inhibitors blocked the ability of 5-HT to increase S6 kinase phosphorylation (Figs. $5 C$, quantitated in $6 A, B$ ).

One model of S6 kinase activation is that the rapamycinsensitive protein FRAP acts to inhibit a constitutively active 


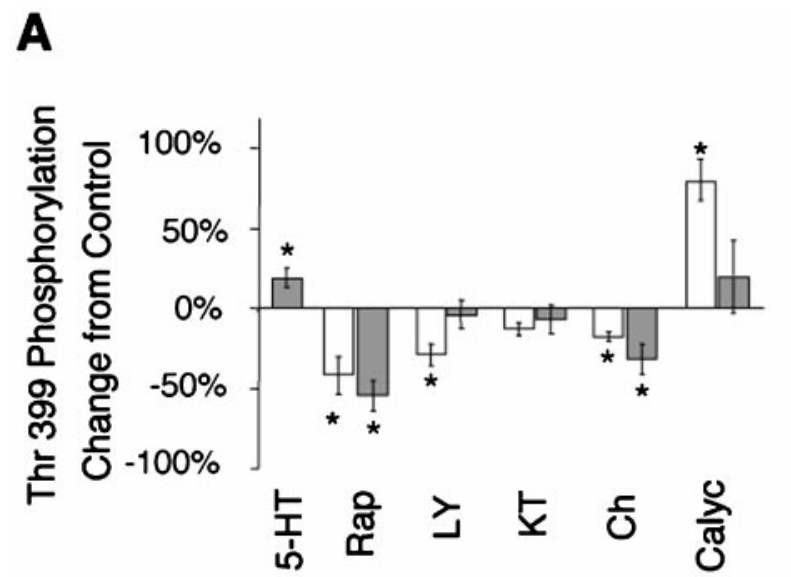

B

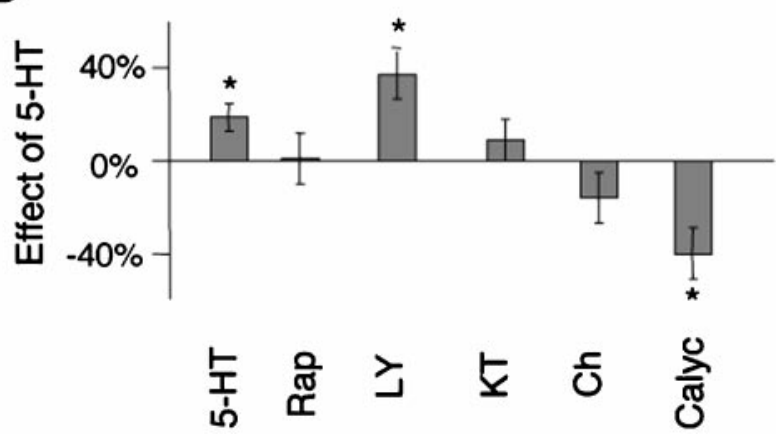

Figure 6. Quantitation of Thr 399 phosphorylation. A, The percentage change in Thr 399 phosphorylation ((experimental - control)/control) * 100) was calculated with the control being aliquots of synaptosomes from the same preparation treated only with low $\mathrm{Ca}^{2+}$-seawater. White bars represent changes with pharmacological agent alone, and shaded bars represent changes in the presence of both serotonin and the pharmacological agent [5-HT, $n=20$; rapamycin (Rap), $n=6$; rapamycin plus 5-HT, $n=6$; LY294002 ( $L Y$ ), $n=6$; LY294002 plus 5-HT, $n=6$; KT5720 $(K T), n=5$; KT5720 plus 5 -HT, $n=5$; chelerythrine $(C h), n=4$; chelerythrine plus 5-HT, $n=4$; calyculin-A (Calyc), $n=7$; calyculin-A plus 5-HT, $n=4$; error bars represent SEM). ${ }^{*} p<0.05$, comparisons between control and treatment; Student's paired $t$ test. $B$, Percentage change in Thr 399 treatment was calculated as above, but now the control was the presence of pharmacological agent as opposed to low $\mathrm{Ca}^{2+}$-free seawater. The experimental value was 5 -HT in the presence of the pharmacological agent. Results from 5-HT alone from $A$ are shown for comparison. Rapamycin, $n=6$; LY294002, $n=6$; KT5720, $n=5$; chelerythrine, $n=4$; calyculin-A, $n=4 .{ }^{*} p<0.05$, comparisons between pharmacological agent and pharmacological agent plus 5-HT; Student's paired $t$ test.

phosphatase (Weng et al., 1995b; Peterson et al., 1999). Thus, a phosphatase inhibitor should mimic the actions of FRAP. This phosphatase has been reported to be particularly sensitive to the phosphatase inhibitor calyculin-A (Parrott and Templeton, 1999), and indeed, the calyculin-A-sensitive phosphatase $2 \mathrm{~A}$ has been reported to associate with S6 kinase (Peterson et al., 1999). We found that treating synaptosomes with calyculin-A led to a large increase in Thr 399 phosphorylation (Figs. 5D, quantitated in $6 A$ ). This increase occluded the ability of 5-HT to further increase Thr 399 phosphorylation. Indeed, in the presence of calyculin-A, 5-HT now led to a decrease in Thr 399 phosphorylation (Figs. $5 D$, quantitated in $6 B$ ).

To determine whether the phosphatase was upstream or downstream of FRAP, we determined whether the effect of calyculin-A could be blocked by rapamycin. The effect of calyculin-A was

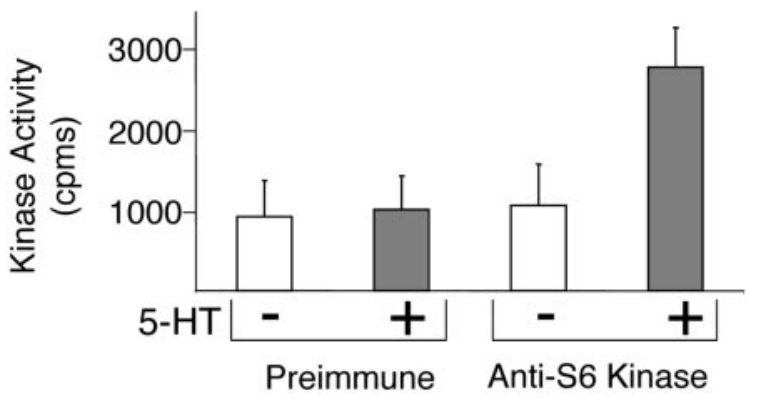

Figure 7. 5-HT increases S6 kinase activity. Batches of synaptosomes from five animals were split into two aliquots. One aliquot was treated with $\mathrm{Ca}^{2+}$-free seawater $(-)$, and the other with $\mathrm{Ca}^{2+}$-free seawater containing $20 \mu \mathrm{M}$ 5-HT (+). The synaptosomes were homogenized, split into two equal fractions, and immunoprecipitated with either preimmune serum or serum for S6 kinase. The immunoprecipitates were then assayed for S6 kinase activity measuring incorporation of $\left[{ }^{32} \mathrm{P}\right] \mathrm{ATP}$ into peptides derived from the Aplysia S6 kinase. Error bars represent SEM from three independent experiments.

insensitive to treatment with rapamycin $(10 \pm 12 \%$, effect of rapamycin on calyculin-treated synaptosomes; $n=3$; SEM) (Fig. $5 E)$; thus, the evidence suggests that a calyculin-A-sensitive phosphatase is downstream of FRAP in Aplysia synaptosomes.

\section{5-HT increases S6 kinase activity}

Although phosphorylation of the PDK-2 site is very closely linked with activation of the kinase (Weng et al., 1998), we wanted to confirm that 5-HT increased S6 kinase activity in synaptosomes. The consensus site for S6 kinase is $\mathrm{R} / \mathrm{KxR} / \mathrm{KxxS}$ (Flotow and Thomas, 1992), and there are two sites in Aplysia S6 that match this consensus (Fig. 2). To determine whether 5-HT increased S6 kinase activity, in vitro kinase assays using peptides derived from the Aplysia S6 sequence were accomplished after immunoprecipitation of S6 kinase from synaptosomes. These assays revealed a low level of basal S6 kinase activity that was significantly increased by 5-HT (Fig. 7). This increase was specific to S6 kinase because 5-HT did not increase kinase activity if preimmune serum was used for the immunoprecipitation (Fig. 7).

\section{5-HT increases the level of S6 and S6 phosphorylation in synaptosomes}

To observe whether activation of S6 kinase led to an increase in phosphorylation of endogenous S6, we raised an antibody to S6. This antibody recognized multiple bands migrating around the expected molecular weight of $31 \mathrm{kDa}$ (Fig. $8 A$ ). It is well known that phosphorylation of S6 causes a shift in the migration of the protein (Thomas et al., 1979; Martin-Perez and Thomas, 1983). Treatment of synaptosomes with 5-HT increased the percentage of slower migrating S6, consistent with an increase in S6 phosphorylation (Fig. $8 A$ ). This increase was not seen in the presence of rapamycin (Fig. $8 A$, quantitated in $C$ ). Strikingly, in many experiments, 5-HT also induced a large rapamycin-sensitive increase in the levels of S6 in synaptosomes (Fig. $8 B$, quantitated in $D)$. Interestingly, the two effects of 5 -HT were inversely correlated (Fig. $8 E$ ). When a large increase in phosphorylation was seen, there was little change in the abundance of S6 (Fig. 8A), and similarly, when there was a large increase in abundance, there was a smaller increase in the relative level of the upper band (Fig. $8 B$ ). This is consistent with 5 -HT-induced production or stabilization of unphosphorylated S6. 

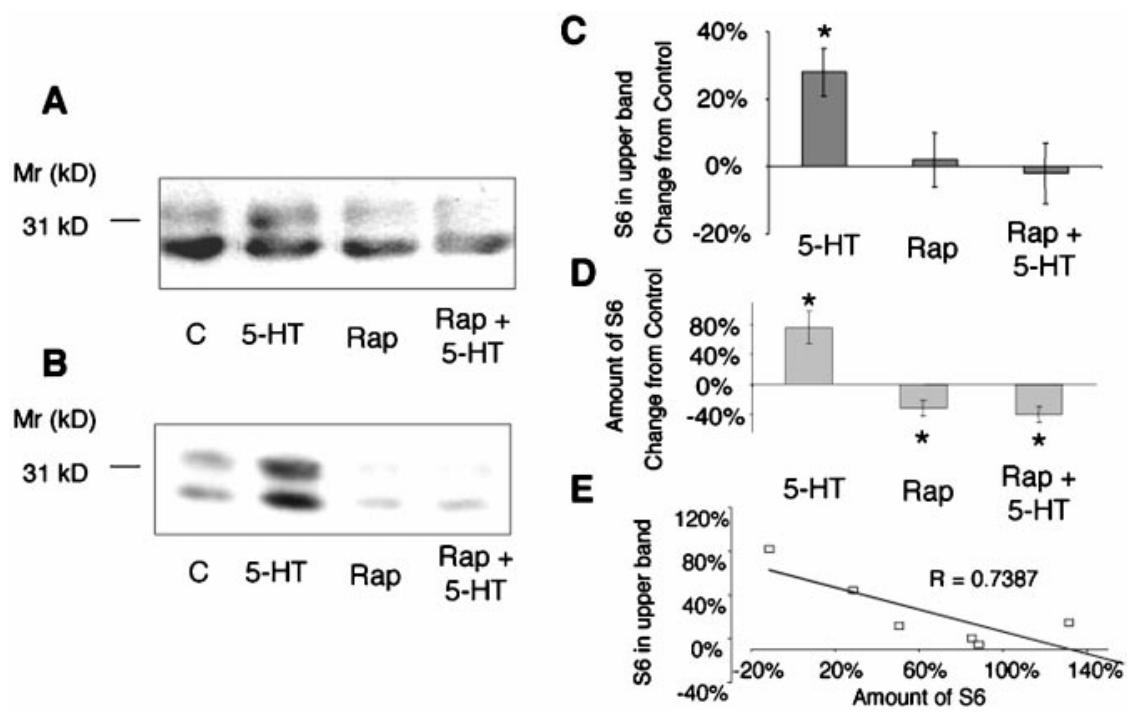

Figure 8. 5-HT increase S6 phosphorylation and the amount of S6 in synaptosomes. Synaptosomes were treated with $\mathrm{Ca}^{2+}$-free seawater or Ca ${ }^{2+}$-free seawater and $20 \mu \mathrm{M} 5$-HT for $25 \mathrm{~min}$ in the presence or absence of $20 \mathrm{~nm}$ rapamycin. Samples were immediately put in Laemmli's buffer, boiled, separated on SDS-PAGE gels, transferred to nitrocellulose, and blotted with the antibody to Aplysia S6. Two experiments are shown, one to illustrate the increase in the percentage in the upper band $(A)$ and the other to illustrate the increase in S6 levels $(B)$. $C$, Quantitation of the percentage change $(($ experimental - control)/control) $* 100)$ in the amount of S6 phosphorylated. The amount of phosphorylation was determined by dividing the immunoreactivity in the upper band by the total immunoreactivity (upper plus lower band). This was then compared with the synaptosomes from the same preparation treated with only $\mathrm{Ca}^{2+}$-free seawater (control); $n=6$; SEM. ${ }^{*} p<0.05$, comparisons between the control and the experimental condition; Student's paired $t$ test . $D$, Quantitation of changes in the level of S6 in synaptosomes. Levels of S6 were first standardized to the total protein loaded in the lane measured using ponceau staining. Because all lanes from one preparation are aliquots, there was never more than a $20 \%$ difference between total levels of proteins in lanes from the same experiment. Each experimental value was then compared with the synaptosomes from the same preparation treated with only $\mathrm{Ca}^{2+}$-free seawater (control); $n=6$; SEM. ${ }^{*} p<0.05$, comparisons between the control and the experimental condition; Student's paired $t$ test. $E$, The change in level of S6 and the change in the phosphorylation of S6 from each preparation of synaptosomes were compared. The increase in phosphorylation and increase in amounts were inversely correlated, suggesting a specific increase in nonphosphorylated S6.

\section{Aplysia PDK-1 binds to and phosphorylates Aplysia S6 kinase}

We were interested in determining whether Aplysia PDK-1 was the primary regulator of Thr 399 phosphorylation. It has been suggested that PDK-1 not only phosphorylates the PDK-1 site (Aplysia Thr 239) but also phosphorylates the PDK-2 site (Aplysia 399) (Balendran et al., 1999). First, we determined whether Aplysia S6 kinase could bind to Aplysia PDK-1, because PDK-1 binds to many of its substrates (Belham et al., 1999). Indeed, GST fusion proteins of either PDK-1 or a mutant in which the catalytic lysine was converted to asparagine [PDK-1 (K-N)] bound to baculovirus-expressed S6 kinase, whereas no binding was seen with GST alone (Fig. 9A). However, we were unable to detect kinase activity from these GST fusion proteins. Therefore, to determine whether PDK could phosphorylate S6 kinase, we took advantage of the fact that, in SF9 cells, overexpressed S6 kinase was primarily unphosphorylated (Fig. $4 C$ ) Thus, we constructed baculovirus vectors for both PDK and PDK (K-N) and expressed PDK in SF9 cells (Fig. 9B).

Coexpression of Aplysia PDK with Aplysia S6 kinase in baculovirus was sufficient to cause a quantitative shift in the molecular weight of S6 kinase (Fig. 10A, quantitated in $C$ ). The mobility shift required active PDK because no shift was seen after expression with PDK (K-N) (Fig. 10A, quantitated in $C$ ). Because PDK phosphorylation in cells may require PI-3 kinase activity (Alessi et al., 1998; Pullen et al., 1998), we also tested overexpression of a baculovirus encoding constitutively active PI-3 kinase. This construct increased PI-3 kinase activity at least 10 -fold in SF9 cell membranes (data not shown). There was no additional shift in S6 kinase when PI-3 kinase was expressed with PDK (Fig. 10 A, quantitated in $C$ ).

\section{A}

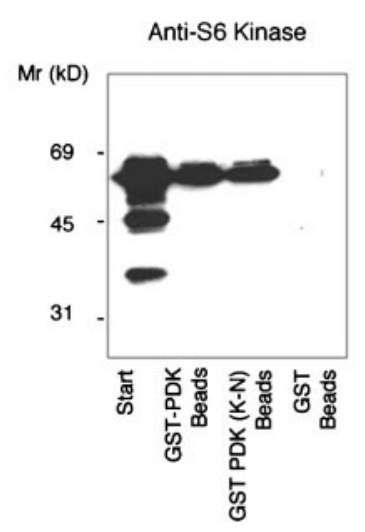

B
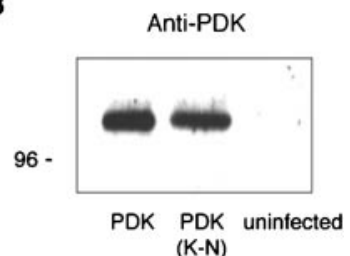

Figure 9. Characterization of Aplysia PDK-1. A, GST-PDK-1 binds to S6 kinase. Extracts from SF9 cells expressing S6 kinase were incubated with glutathionine beads containing equal amounts of GST-PDK-1, GSTPDK-1 (K-N), and 10 times higher levels of GST. Glutathione beads were washed and then eluted with sample buffer, and the eluate were separated on a SDS-polyacrylamide gel, transferred to nitrocellulose, and blotted with the antibody to S6-kinase. Ten percent of the starting material was loaded in lane 1 (Start). B, Expression of PDK-1 and PDK-1 (K-N) in SF9 cells. Extracts of SF9 cells infected with PDK, PDK (K-N), or uninfected cells were separated on SDS-polyacrylamide gels, transferred to nitrocellulose, and blotted with the antibody to PDK-1.

\section{PDK-1 modulates threonine 399 phosphorylation in SF9 cells}

To determine whether the shift in migration was attributable to phosphorylation at Thr 399, we reprobed experiments examining coexpression of PDK and S6 kinase with the phospho-specific 
A
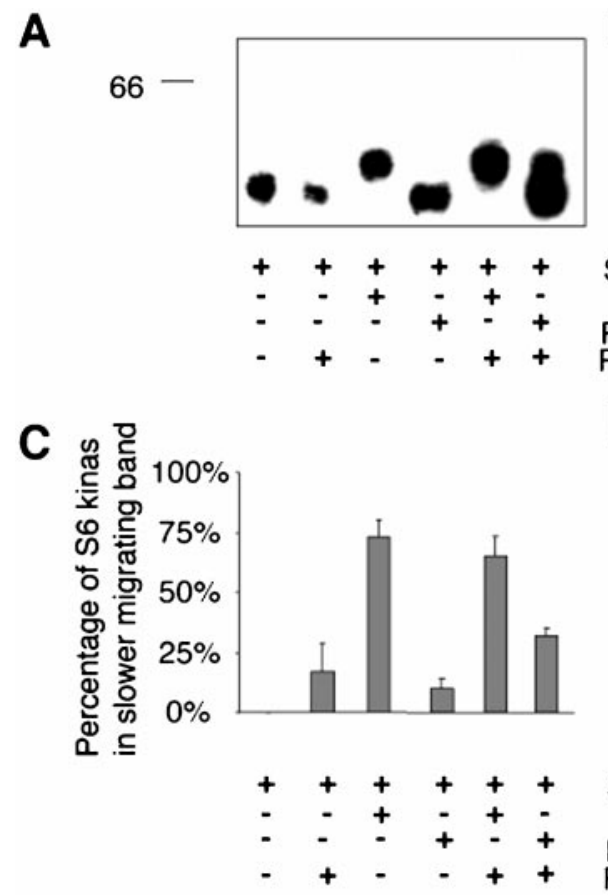

B
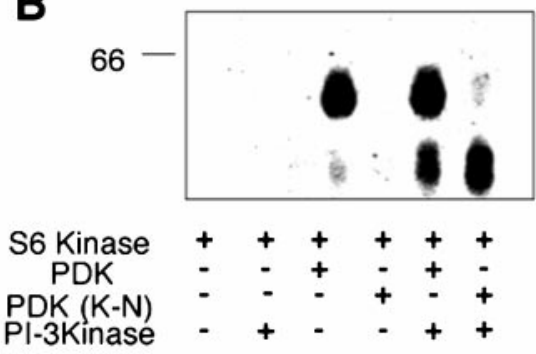

D

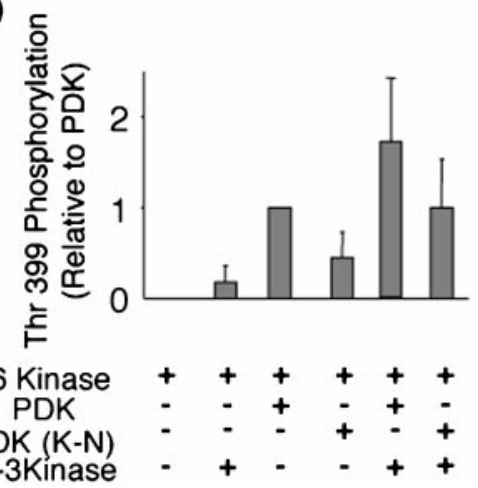

Figure 10. Aplysia PDK-1 phosphorylates Aplysia S6 kinase in SF9 cells. $A$, Coexpression of PDK-1 with S6 kinase in SF9 cells led to a quantitative shift in S6 kinase migration. Extracts from SF9 cells infected with the viruses shown were separated on SDS-polyacrylamide gels, transferred to nitrocellulose, and blotted for S6 kinase. $B$, The blot displayed in $A$ was stripped and reprobed with the phospho-specific antibody to Thr 399 $(B)$. When multiple infections are done, less of each virus is expressed as they all use the same promoter. Thus, we attempted to equalize the levels of S6 kinase by loading increasing levels of SF9 cell extract for multiple infections $(10 \mu \mathrm{l}$, single infections; $20 \mu \mathrm{l}$, double infections; 30 $\mu l$, triple infections). Although only partially successful, neither of our quantitative results rely on equal loading of the gels. $C$, Quantitation of the shift in migration. The percentage of kinase in the slower migrating band was divided by the total immunoreactivity. SEM; $n=4$. $D$, The immunoreactivity to the p-Thr-399 antibody was standardized by the immunoreactivity to the total S6 kinase antibody. All results are standardized to the coinfection with PDK-1 and S6 kinase run on the same gel. SEM; $n=4$

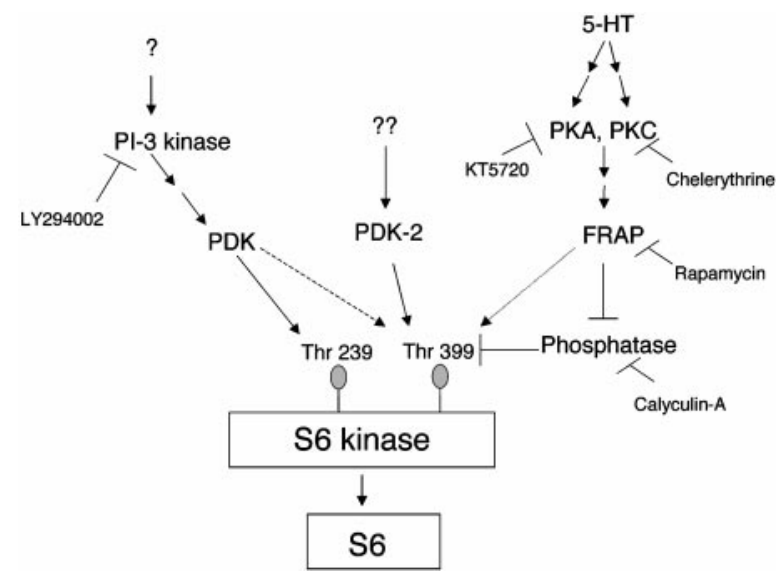

Figure 11. A model for S6 knase activation in Aplysia. Steps involved in phosphorylation of Thr 239 (PDK-1 site) are shown. Arrows indicate positive modulation. Lines with bars are negative modulations. The place which pharmacological agents act is indicated. Multiple arrows indicate missing steps. The dashed arrow between PDK-1 and the PDK-2 site indicates an indirect modulation, and the dashed arrow between FRAP and the PDK-2 site indicates the possibility that FRAP directly phosphorylates this site.

antibody to the PDK-2 site. Coinfection with PDK led to an increase in phosphorylation at Thr 399, and this was associated with an additional shift in migration (Fig. $10 B$, quantitated in $D$ ). Thus, the initial quantitative shift in migration was probably attributable to phosphorylation of the PDK-1 site, Thr 239. Coinfection with a constitutively active PI-3 kinase virus further increased Thr 399 phosphorylation (Fig. 10B, quantitated in D) and led to some additional immunoreactivity that migrated at a lower position that may represent S6 kinase phosphorylated only at Thr 399. However, even under these conditions, very little protein was phosphorylated at Thr 399, because immunoreactivity with the S6 kinase antibody could only be seen comigrating with anti-phospho-Thr 399 immunoreactivity with very long exposures (data not shown). This is in contrast to the quantitative shift in mobility seem with the total antibody to S6 kinase, presumably by complete phosphorylation of Thr 239 (Fig. 10A). Moreover, coinfection with the kinase-inactive PDK also increased Thr 399 phosphorylation in the presence of PI-3 kinase (Fig. $10 B$, quantitated in $D$ ). However, in this case, all of the Thr 399 phosphorylation was seen in a faster migrating band, consistent with the lack of phosphorylation at the PDK-1 site. This faster migrating Thr 399-phosphorylated band was never seen in the nervous system, in which Thr 399 phosphorylation was only observed in the slowest migrating band.

These results suggest that PDK can phosphorylate S6 kinase. PDK also increases phosphorylation at the PDK-2 site, but this is indirect and does not require kinase activity. The increased phosphorylation of Thr 399 may be attributable to modulating the availability of S6 kinase to an endogenous kinase because of binding of S6 kinase to PDK-1.

\section{DISCUSSION}

\section{Activation of S6 kinase in Aplysia}

Our results suggest a model for S6 kinase activation by 5-HT in Aplysia (Fig. 11). Application of 5-HT, through activation of PKA and PKC, increases FRAP activity. FRAP then inactivates a phosphatase that had been constitutively dephosphorylating $\mathrm{Thr}$ 399. This leads to increased phosphorylation of Thr 399 and increased activity of S6 kinase. This pathway does not require PI-3 kinase activity. Similarly, phorbol ester-induced activation of S6 kinase phosphorylation is rapamycin-sensitive but PI-3 kinaseindependent in HEK 293 cells (Herbert et al., 2000).

Thr 399 phosphorylation may also requires previous phosphorylation at the Thr 239 (PDK-1 site), because in synaptosomes, only a single Thr 399 phosphorylated band was seen that comigrates with the slowest migrating band. This is consistent with results from vertebrate S6 kinase (Weng et al., 1998). LY249002, an inhibitor of PI-3 kinase, decreased Thr 399 phosphorylation, possibly through inhibition of Thr 239 phosphorylation or through inhibition of the PDK-2 kinase. Phosphorylation at Thr 239 is probably attributable to phosphorylation by Aplysia PDK-1 
because, in SF9 cells, coinfection of PDK-1 was sufficient to quantitatively shift the migration of S6 kinase.

The PDK-2 kinase is still unidentified, although there is some data suggesting that it is FRAP itself (Burnett et al., 1998a; Isotani et al., 1999). It is unlikely that 5-HT activates S6 kinase by stimulating this kinase. Indeed, in the presence of calyculin-A, 5-HT decreased Thr 399 phosphorylation, consistent with a possible 5-HT-mediated inhibition of the kinase that phosphorylates the PDK-2 site. We have not yet monitored phosphorylation of other important phosphorylation sites in S6 kinase (Fig. 1), and it is possible that 5-HT modifies phosphorylation of these sites as well.

The regulation of S6 kinase in Aplysia synaptosomes shares similarities with its activation in cell lines. Similar to our results, phosphorylation of the PDK-2 site is only seen in the slowest migrating form of S6 kinase (Weng et al., 1998). Thr 399 phosphorylation is highly rapamycin-sensitive in both systems (Weng et al., 1998), and there appear to be an important role for phosphatase regulation in both systems (Peterson et al., 1999). Also, PDK appears to be an upstream kinase in both Aplysia and vertebrates (Alessi et al., 1998; Pullen et al., 1998). The major difference is that activation of PI-3 kinase is not rate-limiting for Thr 399 phosphorylation (Weng et al., 1995a; Gingras et al., 1998; Balendran et al., 1999; Nave et al., 1999). There are a number of plausible explanations for this difference, including different basal levels of PI-3 kinase levels in synaptosomes, alternative pathways of activating FRAP, or alternative regulation of the PDK-2 kinase.

\section{The target of rapamycin}

Our results are consistent with the rapamycin-sensitive step required for the retention of long-term facilitation corresponding to activation of S6 kinase. However, there are other targets for the rapamycin-sensitive enzyme FRAP that also may play a role in the retention of long-term facilitation. Phosphorylation of eIF4EBPs is mediated by FRAP (Brunn et al., 1997). This phosphorylation releases free eIF4E (Lin et al., 1994; Pause et al., 1994), which then can translocate mRNAs to the ribosome. A specific set of mRNAs that have structured $5^{\prime}$ untranslated regions are particularly sensitive to the levels of free eIF4E (Rosenwald et al., 1995; Rousseau et al., 1996). Recently, phosphorylation of a site equivalent to the PDK-2 site in $\mathrm{Ca}^{2+}$-independent PKCs was reported to also be rapamycin-sensitive (Parekh et al., 1999). This site is conserved in the $\mathrm{Ca}^{2+}$-independent PKC Apl II in Aplysia. It will be interesting to determine whether these proteins are also regulated in a rapamycin-sensitive manner in Aplysia neurons.

There are also important aspects of translational regulation at synapses that are independent of rapamycin (Yanow et al., 1998; Casadio et al., 1999). Regulation of translation at synapses is likely to involve multiple independent mechanisms. These include regulation of poly-A addition to mRNAs (Wu et al., 1998), increases in translation initiation (Weiler et al., 1994), and regulation of translation elongation (Scheetz et al., 1997, 2000).

\section{Role for an increase in the presence of translation factors}

5-HT increased S6 kinase activity. We observed both an increase in S6 kinase activity and the percentage of more slowly migrating S6 after addition of 5-HT. We also observed an increase in the levels of S6. Although this may be partially attributable to new synthesis of S6 (S6 is a protein whose translation is normally under regulation of S6 phosphorylation), it may also be that S6 is labile in our preparation, and 5-HT induces change in the conformation or localization of S6 that protects it from degradation.

Activation of the S6 kinase pathway leads to increases in translation of ribosomal proteins and translation factors (Dufner and Thomas, 1999). The increase in ribosomal proteins, such as S6, is unlikely to play an important role in synapse-specific plasticity, because ribosomes are assembled in the nucleus, and any protein made at a synapse would have to translocate back to the nucleus to have any effect on ribosome synthesis. However, the increase in translation factors, such as $\operatorname{eIF} 1 \alpha$ and $\operatorname{eIF} 2 \alpha$, could play an important role in the rapamycin sensitivity of long-term memory. Indeed, preliminary evidence suggests that $\operatorname{eIF} 1 \alpha$ mRNA is translocated to processes, and antibodies against eIF1 $\alpha$ block the retention of long-term facilitation (Hegde et al., 1999). This is consistent with a model in which rapamycin-sensitive translation of translation factors at synapses is crucial for retention of long-term facilitation. This increase in translation factors could lead to a sustained increase in the translational capacity of the synapse, and this may be responsible for the retention of new varicosities by both increasing translation of RNAs that are at the synapse and RNAs that are emanating from the nucleus. Mutation of S6 kinase leads to small cells and small organisms (Shima et al., 1998; Montagne et al., 1999); we suggest it may also lead to smaller synapses.

\section{REFERENCES}

Alessi DR, Kozlowski MT, Weng QP, Morrice N, Avruch J (1998) 3-Phosphoinositide-dependent protein kinase 1 (PDK1) phosphorylates and activates the p70 S6 kinase in vivo and in vitro. Curr Biol 8:69-81.

Balendran A, Currie R, Armstrong CG, Avruch J, Alessi DR (1999) Evidence that 3-phosphoinositide-dependent protein kinase-1 mediates phosphorylation of p70 S6 kinase in vivo at Thr-412 as well as Thr-252. J Biol Chem 274:37400-37406.

Bartsch D, Ghirardi M, Skehel PA, Karl KA, Herder SP, Chen M, Bailey CH, Kandel ER (1995) Aplysia creb2 represses long-term facilitation: relief of repression converts transient facilitation into long-term functional and structural change. Cell 83:979-992.

Belham C, Wu S, Avruch J (1999) Intracellular signalling: PDK1-a kinase at the hub of things. Curr Biol 9:R93-R96.

Brown EJ, Schreiber SL (1996) A signaling pathway to translational control. Cell 86:517-520.

Brown EJ, Beal PA, Keith CT, Chen J, Shin TB, Schreiber SL (1995) Control of p70 s6 kinase by kinase activity of FRAP in vivo. Nature 377:441-446.

Brunn GJ, Hudson CC, Sekulic' A, Williams JM, Hosoi H, Houghton PJ, Lawrence Jr JC, Abraham RT (1997) Phosphorylation of the translational PHAS-1 by the mammalian target of rapamycin. Science 277:99-101.

Burnett PE, Barrow RK, Cohen NA, Snyder SH, Sabatini DM (1998a) RAFT1 phosphorylation of the translational regulators p70 S6 kinase and 4E-BP1. Proc Natl Acad Sci USA 95:1432-1437.

Burnett PE, Blackshaw S, Lai MM, Qureshi IA, Burnett AF, Sabatini DM, Snyder SH (1998b) Neurabin is a synaptic protein linking p70 S6 kinase and the neuronal cytoskeleton. Proc Natl Acad Sci USA 95:8351-8356.

Casadio A, Martin KC, Giustetto M, Zhu H, Chen M, Bartsch D, Bailey $\mathrm{CH}$, Kandel ER (1999) A transient, neuron-wide form of CREBmediated long-term facilitation can be stabilized at specific synapses by local protein synthesis. Cell 99:221-237.

Chin GJ, Shapiro E, Vogel SS, Schwartz JH (1989) Aplysia synaptosomes. I. Preparation and biochemical and morphological characterization of subcellular membrane fractions. J Neurosci 9:38-48.

Dennis PB, Pullen N, Kozma SC, Thomas G (1996) The principal rapamycin-sensitive p70(s6k) phosphorylation sites, T-229 and T-389, are differentially regulated by rapamycin-insensitive kinase kinases. Mol Cell Biol 16:6242-6251.

Dufner A, Thomas G (1999) Ribosomal S6 kinase signaling and the control of translation. Exp Cell Res 253:100-109.

Dyer JR, Sossin WS, Klein M (1996) Cloning and characterization of aplycalcin and Aplysia neurocalcin, two new members of the calmodulin family of small calcium binding proteins. J Neurochem 67:933-942.

Flotow H, Thomas G (1992) Substrate recognition determinants of the mitogen-activated $70 \mathrm{~K}$ S6 kinase from rat liver. J Biol Chem 267:3074-3078. 
Gingras AC, Kennedy SG, O'Leary MA, Sonenberg N, Hay N (1998) 4E-BP1, a repressor of mRNA translation, is phosphorylated and inactivated by the Akt(PKB) signaling pathway. Genes Dev 12:502-513.

Han JW, Pearson RB, Dennis PB, Thomas G (1995) Rapamycin, wortmannin, and the methylxanthine SQ20006 inactivate $\mathrm{p} 70 \mathrm{~s} 6 \mathrm{k}$ by inducing dephosphorylation of the same subset of sites. J Biol Chem 270:21396-21403.

Hegde AN, Casadio A, Martin K, Inokuchi K, Pei W, Giustetto M, Kandel ER, Schwartz JH (1999) Induction of the polypeptide chain elongation factor EF $1 \alpha$ is required for late long-term facilitation in Aplysia. Soc Neurosci Abstr 25:1815.

Herbert TP, Kilhams GR, Batty IH, Proud CG (2000) Distinct signalling pathways mediate insulin and phorbol ester-stimulated eukaryotic initiation factor 4F assembly and protein synthesis in HEK 293 cells. J Biol Chem 275:11249-11256.

Isotani S, Hara K, Tokunaga C, Inoue H, Avruch J, Yonezawa K (1999) Immunopurified mammalian target of rapamycin phosphorylates and activates p70 S6 kinase alpha in vitro. J Biol Chem 274:34493-34498.

Jefferies HB, Fumagalli S, Dennis PB, Reinhard C, Pearson RB, Thomas G (1997) Rapamycin suppresses 5' TOP mRNA translation through inhibition of p70s6k. EMBO J 16:3693-3704.

Lin TA, Kong X. Haystead TA, Pause A, Belsham G, Sonenberg N, Lawrence JJ (1994) PHAS-I as a link between mitogen-activated protein kinase and translation initiation. Science 266:653-656.

Martin-Perez J, Thomas G (1983) Ordered phosphorylation of 40S ribosomal protein S6 after serum stimulation of quiescent 3T3 cells. Proc Natl Acad Sci USA 80:926-930.

Montagne J, Stewart MJ, Stocker H, Hafen E, Kozma SC, Thomas G (1999) Drosophila S6 kinase: a regulator of cell size. Science 285:2126-2129.

Nakhost A, Dyer JR, Pepio AM, Fan X, Sossin WS (1999) Protein kinase $\mathrm{C}$ phosphorylated at a conserved threonine is retained in the cytoplasm. J Biol Chem 274:28944-28949.

Nave BT, Ouwens M, Withers DJ, Alessi DR, Shepherd PR (1999) Mammalian target of rapamycin is a direct target for protein kinase B: identification of a convergence point for opposing effects of insulin and amino-acid deficiency on protein translation. Biochem J 344:427-431.

Parekh D, Ziegler W, Yonezawa K, Hara K, Parker PJ (1999) Mammalian TOR controls one of two kinase pathways acting upon nPKCdelta and nPKCepsilon. J Biol Chem 274:34758-34764.

Parrott LA, Templeton DJ (1999) Osmotic stress inhibits p70/85 S6 kinase through activation of a protein phosphatase. J Biol Chem 274:24731-24736

Pause A, Belsham GJ, Gingras AC, Donze O, Lin TA, Lawrence JJ, Sonenberg N (1994) Insulin-dependent stimulation of protein synthesis by phosphorylation of a regulator of $5^{\prime}$-cap function. Nature 371:762-767.

Pearson RB, Dennis PB, Han JW, Williamson NA, Kozma SC, Wettenhall RE, Thomas G (1995) The principal target of rapamycin-induced p70s6k inactivation is a novel phosphorylation site within a conserved hydrophobic domain. EMBO J 14:5279-5287.

Peterson RT, Schreiber SL (1998) Translation control: connecting mitogens and the ribosome. Curr Biol 8:R248-R250.

Peterson RT, Desai BN, Hardwick JS, Schreiber SL (1999) Protein phosphatase $2 \mathrm{~A}$ interacts with the $70-\mathrm{kDa}$ S6 kinase and is activated by inhibition of FKBP12-rapamycinassociated protein. Proc Natl Acad Sci USA 96:4438-4442.

Pullen N, Dennis PB, Andjelkovic M, Dufner A, Kozma SC, Hemmings BA, Thomas G (1998) Phosphorylation and activation of p70s6k by PDK1. Science 279:707-710.

Rosenwald IB, Kaspar R, Rousseau D, Gehrke L, Leboulch P, Chen JJ, Schmidt EV, Sonenberg N, London IM (1995) Eukaryotic translation initiation factor 4E regulates expression of cyclin D1 at transcriptional and post-transcriptional levels. J Biol Chem 270:21176-21180.

Rousseau D, Kaspar R, Rosenwald I, Gehrke L, Sonenberg N (1996) Translation initiation of ornithine decarboxylase and nucleocytoplasmic transport of cyclin D1 mRNA are increased in cells overexpressing eukaryotic initiation factor 4E. Proc Natl Acad Sci USA 93:1065-1070.

Scheetz AJ, Nairn AC, Constantine-Paton M (1997) $N$-methyl-Daspartate receptor activation and visual activity induce elongation factor-2 phosphorylation in amphibian tecta: a role for $N$-methyl-Daspartate receptors in controlling protein synthesis. Proc Natl Acad Sci USA 94:14770-14775.

Scheetz AJ, Nairn AC, Constantine-Paton M (2000) NMDA receptormediated control of protein synthesis at developing synapses. Nat Neurosci 3:211-216.

Schuman EM (1997) Synapse specificity and long-term information storage. Neuron 18:339-342.

Shima H, Pende M, Chen Y, Fumagalli S, Thomas G, Kozma SC (1998) Disruption of the p70(s6k)/p85(s6k) gene reveals a small mouse phenotype and a new functional S6 kinase. EMBO J 17:6649-6659.

Sossin WS (1996) Mechanisms for the generation of synapse specificity in long-term memory: the implications of a requirement for transcription. Trends Neurosci 19:215-218.

Steward O, Banker GA (1992) Getting the message from the gene to the synapse: sorting and intracellular transport of RNA in neurons. Trends Neurosci 15:180-186.

Stewart MJ, Berry CO, Zilberman F, Thomas G, Kozma SC (1996) The Drosophila p70s6k homolog exhibits conserved regulatory elements and rapamycin sensitivity. Proc Natl Acad Sci USA 93:10791-10796.

The C. elegans Sequencing Consortium (1998) Genome sequence of the nematode $C$. elegans: a platform for investigating biology. Science 282:2012-2018

Thomas G, Siegmann M, Gordon J (1979) Multiple phosphorylation of ribosomal protein S6 during transition of quiescent 3T3 cells into early G1, and cellular compartmentalization of the phosphate donor. Proc Natl Acad Sci USA 76:3952-3956.

Weiler IJ, Wang X, Greenough WT (1994) Synapse-activated protein synthesis as a possible mechanism of plastic neural change. Prog Brain Res 100:189-194.

Wells DG, Richter JD, Fallon JR (2000) Molecular mechanisms for activity-regulated protein synthesis in the synapto-dendritic compartment. Curr Opin Neurobiol 10:132-137.

Weng QP, Andrabi K, Klippel A, Kozlowski MT, Williams LT, Avruch J (1995a) Phosphatidylinositol 3-kinase signals activation of p70 S6 kinase in situ through site-specific p70 phosphorylation. Proc Natl Acad Sci USA 92:5744-5748.

Weng QP, Andrabi K, Kozlowski MT, Grove JR, Avruch J (1995b) Multiple independent inputs are required for activation of the p70 S6 kinase. Mol Cell Biol 15:2333-2340.

Weng QP, Kozlowski M, Belham C, Zhang A, Comb MJ, Avruch J (1998) Regulation of the p70 S6 kinase by phosphorylation in vivo. Analysis using site-specific anti-phosphopeptide antibodies. J Biol Chem 273:16621-16629.

Westphal RS, Coffee Jr RL, Marotta A, Pelech SL, Wadzinski BE (1999) Identification of kinase-phosphatase signaling modules composed of p70 S6 kinase-protein phosphatase 2A (PP2A) and p21-activated kinase-PP2A. J Biol Chem 274:687-692.

Wu L, Wells D, Tay J, Mendis D, Abbott MA, Barnitt A, Quinlan E, Heynen A, Fallon JR, Richter JD (1998) CPEB-mediated cytoplasmic polyadenylation and the regulation of experience-dependent translation of alpha-CaMKII mRNA at synapses. Neuron 21:1129-1139.

Yanow SK, Manceau F, Hislop J, Castellucci VF, Sossin WS (1998) The biochemical pathways by which serotonin regulates translation in the nervous system of Aplysia. J Neurochem 70:572-583. 